\title{
Mesoporous titanium phosphates and related molecular sieves: Synthesis, characterization and applications
}

\author{
ASIM BHAUMIK \\ Department of Materials Science, Indian Association for the Cultivation of \\ Science, Jadavpur, Kolkata 700 032, India \\ e-mail: msab@mahendra.iacs.res.in
}

\begin{abstract}
Titanium (IV) phosphates TCM-7 and -8 with mesoporous cationic framework topologies using both cationic and anionic surfactants have been synthesized. Experimental data suggest the stabilization of the tetrahedral state of Ti in TCM-7/8 (O-P-O-Ti-O-, at Ti/P = 1:1) vis-à-vis the most stable octahedral state of $\mathrm{Ti}$ in the rutile/anatase or pure mesoporous $\mathrm{TiO}_{2}$. Mesoporous TCM-7 and -8 show anion exchange capacity due to the framework phosphonium cation and cation exchange capacity due to defective $\mathrm{P}-\mathrm{OH}$ groups. Grafting the organic functionality in the surface or bridging the organic moiety in between the inorganic phosphorus precursors can enhance hydrophobicity of these materials similar to that of mesoporous silica materials. The high catalytic activity in the liquid phase partial oxidation of cyclohexene over such organically surface modified mesoporous titanium phosphate using a dilute $\mathrm{H}_{2} \mathrm{O}_{2}$ oxidant supports the tetrahedral coordination of $\mathrm{Ti}$ in these materials. These materials also show excellent photocatalytic activity in the production of $\mathrm{H}_{2}$ by photo-reduction of water under UV light irradiation.
\end{abstract}

Keywords. Titanium phosphate; zeolite; ion-exchanger; cationic framework; oxidation catalysis; photocatalysis.

\section{Introduction}

Aluminosilicate zeolites ${ }^{1-3}$ with an anionic framework and cation exchange capacity have been extensively studied and used as acid catalysts, adsorbents and ion exchangers in the chemical and petrochemical industries. Phosphate-based molecular sieves ${ }^{4-6}$ with mostly a neutral frameworks have also attracted widespread attention of the academia and industry because of their interesting 2D and 3D framework topologies. On the other hand, commercial anion exchangers are mostly organically based, such as anion exchange resins. Although the cation exchange materials are very common for inorganic materials (e.g. zeolites), anion exchangeable inorganic materials are very rare. Hydrotalcite ${ }^{7}$ and mesoporous aluminophosphate derived from polyoxometalate clusters ${ }^{8,9}$ are the only examples of such a class of material. Apart from that, UV-Vis light-driven photocatalysts are titanium-based materials. This has been urged from the viewpoint of not only efficient decomposition of water ${ }^{10-12}$ to produce hydrogen, as an alternative energy source but also of reduction of carbon dioxide, a greenhouse gas. Synthesis of Ti-containing micro and mesoporous silica materials is also of outstanding interest because of their remarkable applicability to liquid phase partial oxidation ${ }^{13}$ reactions. However, the small pores of such highly active microporous titanium silicates (viz. TS-1, Ti-beta etc.) restricts their application to only smaller organic molecules $\left(\mathrm{C}_{3}-\mathrm{C}_{7}\right)^{13}$. Thus inorganic mesoporous materials with a framework $\mathrm{Ti}$ and zeolite-like ion-exchange properties are highly 
desirable. Although there have been many reports on layered ${ }^{14}$ and open-framework ${ }^{15}$ titanium phosphates, there are very few reports on porous titanium phosphates ${ }^{16}$. Although mesoporous titanium phosphate has large potential to be used as catalysts for liquid phase oxidation reactions and photoreactions, almost no attention was paid to the coordination of $\mathrm{Ti}$ and catalysis in such reactions so far. We have succeeded in the synthesis of mesoporous titanium phosphates, by using not only cationic surfactants but also anionic surfactants ${ }^{17}$. Here, the pore wall of these mesoporous titanium phosphates composed of $\mathrm{Ti}, \mathrm{P}$ and $\mathrm{O}$ connectivities. The unusual ion-exchange properties of these materials are very important to use these materials as a catalyst, because reactants can be adsorbed onto the charged surface of the catalyst. For the liquid phase partial oxidation reactions usually dilute aqueous $\mathrm{H}_{2} \mathrm{O}_{2}$ or tert-butylhydroperoxide are used as oxidant. These oxidants are commercially available in their aqueous solution. The surface of the mesoporous materials are usually hydrophilic in nature containing very large concentrations of defect $-\mathrm{OH}$ groups, which can preferentially adsorb the water molecules instead of the organic reactant. In order to have good catalytic activity thus the catalyst surface must have to be hydrophobic in nature. Introducing organic functionalities in the mesoporous pore wall can enhance hydrophobicity of these materials. Such organic-inorganic hybrid mesoporous silica materials have attracted wide attention in the recent years ${ }^{18,19}$.

\section{Experimental}

Cationic surfactants, like octadecyltrimethylammonium chloride (ODTMACl) and octadecyltrimethylammonium bromide (ODTMABr), and anionic surfactants, like sodium dodecylsulphate (SDS) and dodecyl p-benzenesulphonic acid (DBSA), were used as structure-directing agents for the synthesis of TCM-7 and -8 .

\subsection{Synthesis of TCM-7 and -8}

Cationic surfactant octadecyltrimethyl ammonium halides (ODTMACl and ODTMABr for TCM-7 and -8, respectively) were found to be efficient structure-directing agents (SDAs) for the synthesis of mesoporous titanium phosphates when titanium isopropoxide $\mathrm{Ti}(\mathrm{OPr})_{4}$ was used as the Ti source. TCM-7 and -8 can also be synthesized efficiently in the presence of anionic surfactants, i.e. SDS (TCM-7) and DBSA (TCM-8), with $\mathrm{TiCl}_{4}$ as the Ti source. In a typical synthesis with a cationic surfactant, ODTMABr/Cl was dissolved in water and the required amount of $\mathrm{H}_{3} \mathrm{PO}_{4}$ was added to it, and then the mixture was homogenized by vigorous stirring. Then $\mathrm{Ti}(\mathrm{OPr})_{4}$ dissolved in an equal amount $(\mathrm{w} / \mathrm{w})$ of isopropyl alcohol was added slowly to the mixture. After $1 \mathrm{~h}$ stirring, the $\mathrm{pH}$ of the solution was adjusted to $\approx 4.0$ with liquid ammonia. For anionic surfactants, first an SDA was dissolved along with the required $\mathrm{H}_{3} \mathrm{PO}_{4}$ in water, and then $\mathrm{TiCl}_{4}$ was added to the mixture slowly. Finally the $p \mathrm{H}$ was adjusted to ca. 4.0 and additional $\mathrm{H}_{2} \mathrm{O}$ was added. Then the resultant slurry was heated at $318-348 \mathrm{~K}$ for 1 day under autogeneous pressure. For Me-TCM-7, equimolar concentrations of $\mathrm{H}_{3} \mathrm{PO}_{4}$ and methylphosphonic acid dimethyl ester were used as phosphorous sources. For the synthesis of pure titania with a mesoscopic framework, i.e. $\mathrm{TiO}_{2}-\mathrm{SDS}$ and $\mathrm{TiO}_{2}-\mathrm{DBSA}$, SDS and DBSA were used as surfactants, respectively. In a typical synthesis of $\mathrm{TiO}_{2}-$ DBSA, $16.5 \mathrm{~g}$ of DBSA was dissolved in $150 \mathrm{ml}$ water and $\mathrm{TiCl}_{4}(18.9 \mathrm{~g})$ was added dropwise to it with constant stirring. After $1 \mathrm{~h}$ the $p \mathrm{H}$ of the solution was adjusted to 
$\approx 4.0$ with liquid ammonia and the resultant slurry was heated at an elevated temperature. After the synthesis, the product was filtered off, washed with water and then dried under vacuum at room temperature. Cationic surfactants were removed from the as-synthesized materials by $\mathrm{HCl} / \mathrm{EtOH}$ treatment whereas for the removal of anionic surfactant $\mathrm{NH}_{4} \mathrm{OH} / \mathrm{EtOH}$ extraction for $4 \mathrm{~h}$ at $298 \mathrm{~K}$ was followed. Typically, $2 \mathrm{~g}$ as-synthesized material was treated with $2 \mathrm{ml} 2 \mathrm{~mol} \% \mathrm{HCl}$ or $2 \mathrm{ml} 25 \%$ aqueous $\mathrm{NH}_{4} \mathrm{OH}$ in $150 \mathrm{ml}$ EtOH. The anion exchange capacity of these titanium phosphates was evaluated by potentiometric titration of the filtrates obtained on treatment of the Cl-forms of TCM-7/8 samples with $\mathrm{NH}_{4} \mathrm{OH} / \mathrm{H}_{2} \mathrm{O}$. An aqueous $\mathrm{AgNO}_{3}$ solution was used for the titration. Cation exchange capacities were measured by the acid-base titration and by chemical analysis of the exchanged solid.

\subsection{Characterization of titanium phosphates}

XRD patterns were obtained with a Rigaku RINT-2200 diffractometer using $\mathrm{Cu}-\mathrm{K}_{\alpha}$ radiation. Transmission electron micrographs (TEMs) were obtained with a JEOL JEM$200 \mathrm{CX}$ at an accelerating voltage of $200 \mathrm{kV}$. Scanning electron micrographs (SEMs) for various samples were obtained with a JEOL JSM-890. Nitrogen adsorption isotherms were obtained with a Quantachrome Autosorb-1 at $77 \mathrm{~K}$. Before the adsorption measurements all the samples were evacuated for $2 \mathrm{~h}$ at room temperature. UV-Vis diffuse reflectance spectra were obtained with a JASCO V-570 equipped with an integrating sphere. FT-IR spectra of as-synthesized and surfactant-free samples were recorded with a JASCO FT/IR-5M using $\mathrm{KBr}$ pallet technique. For ${ }^{31} \mathrm{P}$ MAS NMR measurements, a Bruker MSL-300WB spectrometer was used at $121.49 \mathrm{MHz}$. The chemical shifts on ${ }^{31} \mathrm{P}$ NMR were referenced to $\mathrm{H}_{3} \mathrm{PO}_{4}$ at $0 \mathrm{ppm}$. Chemical analysis of various samples was carried out by ICP. Liquid phase oxidation reactions were carried out in two-necked round bottom flasks fitted with a condenser and placed in an oil bath at $333 \mathrm{~K}$ with vigorous stirring. Then the reaction products were analysed by capillary GC (using Agilent 4890D with FID), and identified using known standards and GC-MS.

\section{Results and discussion}

\subsection{Characterization of mesophase and microstructure}

From the XRD patterns the products were classified into two types of mesophases, TCM7 and TCM-8. Typical XRD patterns of the as-synthesized TCM-7 and TCM-8 synthesized using ODTMACl and ODTMABr are shown in figure 1. TCM-7 gave a single low-angle peak and no distinctive higher order peaks. TEM showed that a portion of the hexagonal arrangement of uniform mesopores existed in the TCM-7 mesophase. These results suggest that TCM-7 have a low-ordered two-dimensional hexagonal (p6mm) mesophase. The peak positions remained almost unchanged after removal of the surfactant, although the intensity decreased. TCM-8, on the other hand, showed some notable peaks in the low-angle region, suggesting the formation of another mesophase. TEM image of this sample show a lamellar structure. It is important to note that the use of SDS as an SDA in the synthesis of TCM-7 along with $\mathrm{TiCl}_{4}$ as the Ti source often leads to other lamellar mesophases at low temperature. This can be overcome by increasing the hydrothermal synthesis temperature. However, with DBSA as an SDA, no 
lamellar phase was observed. Chemical analysis of these titanium phosphates after the extraction revealed the absence of any organic SDA.

In figure 2, $\mathrm{N}_{2}$ adsorption/desorption isotherms for Me-TCM-7 (a, surface area $710 \mathrm{~m}^{2} \mathrm{~g}^{-1}$, pore diameter $28.7 \AA$ ), TCM-7 (b, surface area $548 \mathrm{~m}^{2} \mathrm{~g}^{-1}$, pore diameter $31 \cdot 3 \AA$ ), and TCM-8 (c, surface area $420 \mathrm{~m}^{2} \mathrm{~g}^{-1}$, pore diameter $27.4 \AA$ ) are shown. These isotherms were type IV in nature ${ }^{20,21}$. The corresponding pore size distributions (figure 2 , inset) showed that these materials have narrow pore size distributions. The pore diameters of the mesoporous titanium phosphates were 27.4-31.3 $\mathrm{A}$. These were almost comparable to those of mesoporous silicas prepared using the same surfactants. The BET surface areas of these mesoporous titanium phosphates were very high vis-à-vis mesoporous $\mathrm{TiO}_{2}$, e.g. as high as $701 \mathrm{~m}^{2} \mathrm{~g}^{-1}$ for sample 2, this being the maximum. The pore walls were relatively thicker $(42.8$ and $29.0 \AA$ ) for samples 1 and 2 , respectively, than those of siliceous MCM-41 materials (10-20 ̊) ${ }^{20}$.

Since there were no noticeable high angle reflections in the XRD patterns of these mesoporous titanium phosphates, the pore walls must be amorphous in nature. The TCM7 and -8 samples exhibited unusually high anion-exchange capacities, $4.7-5.4 \mathrm{mmol} \mathrm{g}{ }^{-1}$. These values are considerably higher than those of other well-known anion exchangers, such as ion-exchange resins (1-4 $\left.\mathrm{mmol} \mathrm{g}^{-1}\right)$ and aluminophosphate mesoporous materials (1-4 mmol g $\left.{ }^{-1}\right)^{9}$. The anion exchange capacities are almost equivalent to the contents of $\mathrm{Ti}$ and $\mathrm{P}$ atoms $\left(5.6 \mathrm{mmol} \mathrm{g}^{-1}\right)$ in these materials. This suggests that the anion-exchange sites are generated in the framework due to the alternate arrangement of $\mathrm{Ti}$ and $\mathrm{P}$ tetrahedra whose corner is shared by oxygen atoms.

${ }^{31}$ P MAS NMR spectra of the titanium phosphate samples showed a broad signal with chemical shifts between 10 to $-25 \mathrm{ppm}$. The TCM-7-ODTMACl materials before and after extraction of the surfactant gave intense peaks with chemical shifts of -4.5 and $-5.0 \mathrm{ppm}$, respectively. An additional peak at $40 \mathrm{ppm}$ was observed for the Me-TCM-7SDS material, which was assigned as phosphorous attached to a methyl group. The TCM8 materials also showed broad peaks with chemical shifts of -1.8 and $-5.1 \mathrm{ppm}$. These

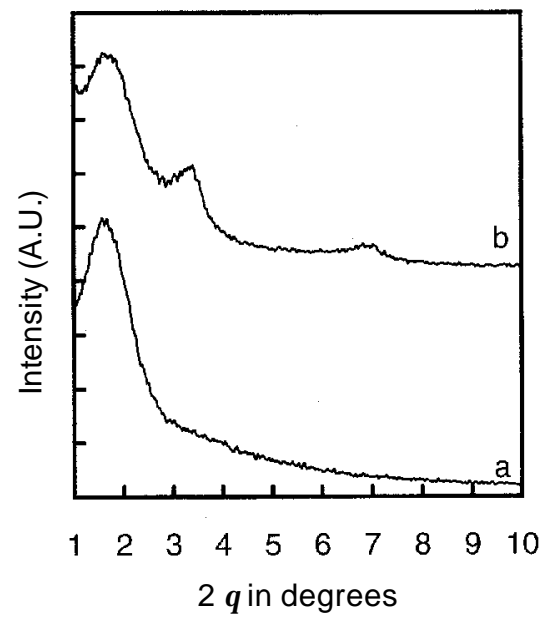

Figure 1. XRD patterns of the as-synthesized TCM-7 (a, sample 1) and TCM-8 (b, sample 4). 


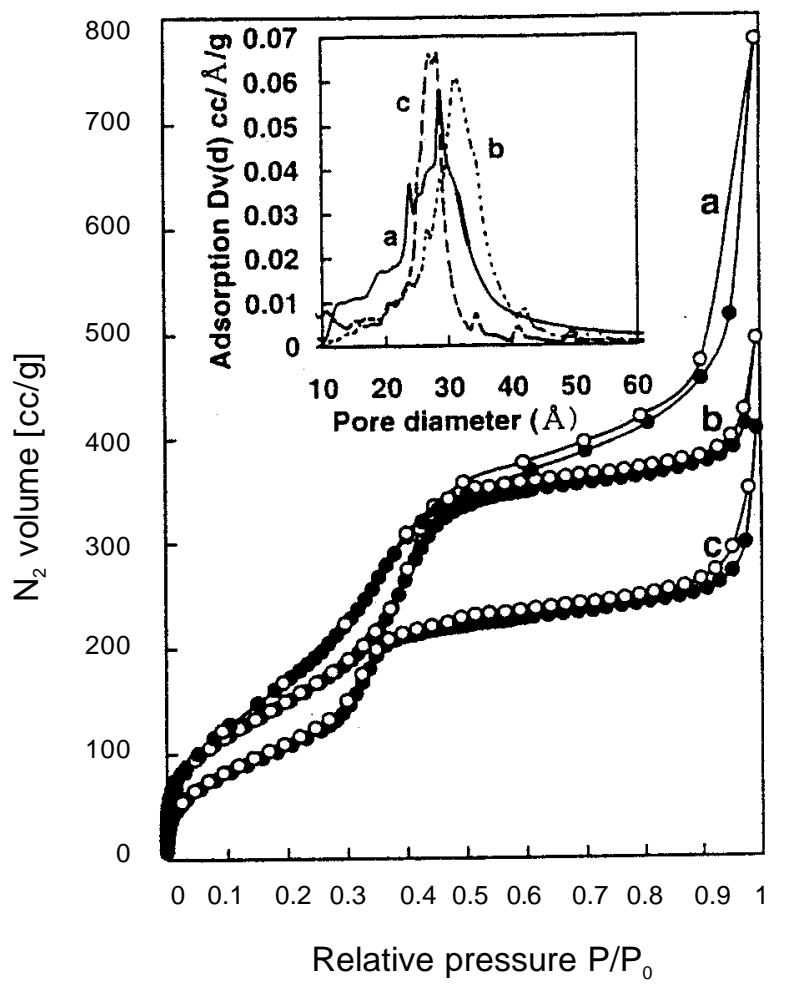

Figure 2. $\mathrm{N}_{2}$ adsorption isotherms for Me-TCM-7 (a, sample 2), TCM-7 (b, sample 1), and TCM-8 (c, sample 4) at $77 \mathrm{~K}$, recorded with an AUTOSORB-1, QUANTACHROME; pore size distributions $(\mathrm{BJH})$ are shown in the inset. Adsorption points are indicated by filled circles and those of desorption by filled triangles.

peaks can be assigned to a mixture of tetrahedral $\mathrm{P}$ environments with connectivity 3 and $4\left[\left(\mathrm{P}(\mathrm{OTi})_{3} \mathrm{OH}\right.\right.$ and $\left.\mathrm{P}(\mathrm{OTi})_{4}\right)$, respectively. Mesostructured $\mathrm{AlPO}_{4}$ materials show signals between -1.4 to $-1.9 \mathrm{ppm}$ due to $\mathrm{PO}_{4}$ tetrahedras. Tetrahedral phosphorous in the neutral microporous aluminophosphate materials shows a strong sharp band at around -28-30 ppm (with respect to $\mathrm{H}_{3} \mathrm{PO}_{4}$ ) in the ${ }^{31} \mathrm{P}$ MAS NMR spectra. Due to the lack of resolution the relative concentrations were not obtained from these spectra. Although the change in chemical shift during removal of the surfactant was small $(0.5 \mathrm{ppm})$ for TCM7-ODTMACl, it was large $(8.8 \mathrm{ppm}$, from -9.8 to $-1.0 \mathrm{ppm})$ for Me-TCM-7-SDS. This large change in the chemical shift may be attributable to the direct interaction between the phosphonium cations $\left(\mathrm{P}^{+}\right)$and anions $\left(\mathrm{SDS}^{-}\right.$or $\left.\mathrm{OH}^{-}\right)$for the Me-TCM-7-SDS system, vis-à-vis indirect interaction between $\mathrm{P}_{-} \mathrm{O}^{-}$and cations $\left(\mathrm{ODTMA}^{+}\right.$or $\left.\mathrm{H}^{+}\right)$for the TCM-7ODTMACl system.

The UV-Vis spectra of the titanium phosphate materials showed a very strong absorption band in the $220-330 \mathrm{~nm}$ wavelength region (figure 3, curves a and $\mathrm{b}$, due to the electronic transition from $\mathrm{O}^{2-} 2 p$ to $\mathrm{Ti}^{4+} 3 d$ orbitals). The mesoporous $\mathrm{TiO}_{2}$ samples synthesized with SDS and DBSA in the absence of $\mathrm{H}_{3} \mathrm{PO}_{4}$ show an absorption edge at $390 \mathrm{~nm}$. This band is similar to that of anatase titania and can be attributed to the 
octahedral coordination of $\mathrm{Ti}$ in the $\mathrm{TiO}_{2}$ network. A similar high energy absorption edge due to tetrahedral coordination of $\mathrm{Ti}$ has been observed for mesoporous titanosilicate $(300-330 \mathrm{~nm})^{22}$, Ti-exchanged Y-zeolite $(320 \mathrm{~nm})^{18}$, and Ti-containing amorphous silica $(325-350 \mathrm{~nm})^{23}$. The high-energy absorption band of titanium phosphates indicates that the tetrahedral coordination of $\mathrm{Ti}$ is dominant in these materials. Microporous titanium silicate TS-1, with tetrahedral Ti gives a strong absorption band at 200-220 nm. This high-energy absorption band is attributable to the low content of Ti (2-2.2 mole\%) of TS1 , the titanium phosphates studied here having a high content of $\mathrm{Ti}$ ( $32 \mathrm{~mole} \%)$. An increase in Ti loading always leads to a considerable shift of UV-Vis absorption to a higher wavelength ${ }^{23}$. The local environment of Ti also plays a crucial role in the shift of the absorption band. The environment with four -O-P attached to Ti in TCM-7/8 instead of four -O-Si in TS-1 may be responsible for this shift. These results indicate the presence of tetrahedrally coordinated $\mathrm{Ti}$ in the mesoporous titanium phosphates. However, little shift of this charge transfer band to low energy region for mesoporous titanium phosphates vis-à-vis Ti-exchanged Y-zeolite or TS-1 suggests the presence of a partial Ti with 5- or 6-fold coordination in the sample. These Ti species are attributable to the extra-framework $\mathrm{TiO}_{2}$. However, no peak corresponding to $\mathrm{TiO}_{2}$ (anatase/rutile with octahedral Ti) was observed in the XRD patterns of these titanium phosphate materials.

In the FT-IR spectra of TCM-7 after surfactant removal is shown. Broad bands in the hydroxyl region with maximum at $3400 \mathrm{~cm}^{-1}$ were observed. This corresponds to $\mathrm{O}-\mathrm{H}$ stretching vibration of the residual water, exchangeable $\mathrm{OH}^{-}$and defective $\mathrm{OH}$. The Ti-O-P framework vibrations, which appear at $1000-1050 \mathrm{~cm}^{-1}$, become broad after surfactant removal. This band was absent for the mesoporous $\mathrm{TiO}_{2}$, which is free of phosphorous, suggesting a $\mathrm{Ti}-\mathrm{O}-\mathrm{P}$ network in the mesoporous titanium phosphates. Along with the anion exchange property, a cation exchange property was observed for TCM-7/8 due to the defective $\mathrm{P}-\mathrm{OH}$ groups. Unlike in silanols $(\mathrm{Si}-\mathrm{OH})$, in which $\mathrm{O}-\mathrm{H}$ bonding is purely covalent, the high ionic character of the $\mathrm{O}-\mathrm{H}$ bond in the $\mathrm{P}-\mathrm{O}^{-} \mathrm{H}^{+}$is responsible for this cation exchange capacity. For TCM-7 and Me-TCM-7, estimated

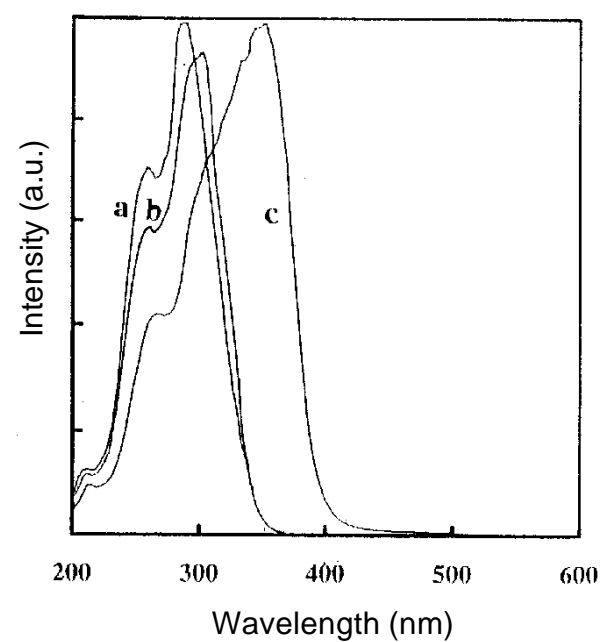

Figure 3. UV-Vis diffuse reflectance spectra of samples 1 (a) 2 (b) and 6 (c) recorded with a JASCO V-570 equipped with an integrating sphere. 
anion-exchange capacities (determined with the $\mathrm{AgNO}_{3}$ titration method) were 5.4 and $5 \cdot 3 \mathrm{mmol} \mathrm{g}^{-1}$, respectively.

\subsection{Proposed structure}

A model is proposed for the Ti, $\mathrm{P}$ and $\mathrm{O}$ connectivities in the framework of the titanium phosphate mesoporous materials based on the above results, as shown in figure 4. Ti and $\mathrm{P}$ have regular alternating tetrahedral arrangements. This model explains the anion and cation exchange capacities of these materials. Both cationic and anionic surfactants can form this framework structure. Whereas in the cases of using the anionic surfactants an $\mathrm{I}^{+} \mathrm{S}^{-}$(where $\mathrm{I}=$ inorganic framework, $\mathrm{S}=$ surfactant) assembly explains the mechanism of formation of the mesoporous titanium phosphate materials, $\mathrm{I}^{-} \mathrm{S}^{+}$and $\mathrm{I}^{+} \mathrm{X}^{-} \mathrm{S}^{+}$miceller assemblies ${ }^{24}$ can explain those using the cationic surfactants. $\mathrm{H}_{2} \mathrm{O}$ vapour adsorption/ desorption isotherms for TCM-7 show a type IV isotherm corresponding to large capillary condensation for the mesophase and hysteresis together with a great level of water vapour absorption at low $P / P_{0}$. At low water vapor pressure large amount of adsorption indicates strong interaction between the water and the solid surface. Such a high level of $\mathrm{H}_{2} \mathrm{O}$ adsorption at low $P / P_{0}$ has been observed for Al-rich aluminosilicates and this adsorption was attributed to the very strong adsorption of water at the Al sites, the level of adsorption linearly increasing with the number of framework Al per unit cell. For pure silica mesoporous materials ${ }^{25,26}$ a type $V$ isotherm with very little $\mathrm{H}_{2} \mathrm{O}$, adsorption of water at low $P / P_{0}$ was observed in the first adsorption/desorption cycle, indicating a very weak interaction between the $\mathrm{H}_{2} \mathrm{O}$ and the surface. The large level of water adsorption at low $P / P_{0}$ suggests the generation of a charge and exchangeable sites for the 1:1 correspondence of $\mathrm{Ti}$ and $\mathrm{P}$ in these mesoporous titanium phosphate materials.

\subsection{Catalysis}

3.3a Liquid phase oxidation catalysis: SEM photographs of TCM-7 and -8 show very small cubic to spherical crystals of $20-40 \mathrm{~nm}$ in size form large spherical aggregates of $0 \cdot 1$ to $0.2 \mu \mathrm{m}$ in size. These nano-range particles of these titanium phosphate materials are quite uniform, unlike in the case of mesoporous silicas, where the particle size usually varies in 1-10 ìm range. Mesoporous materials with a very small particle size have been in great demand since their discovery ${ }^{20}$ as this is an essential criterion for an efficient catalyst. Titanium silicates, especially TS- ${ }^{27}$, with particle size $100-200 \mathrm{~nm}$ have been extensively studied in a variety of organic reactions using dilute hydrogen peroxide as oxidant. The presence of a tetrahedral framework Ti, hydrophobicity and a small particle

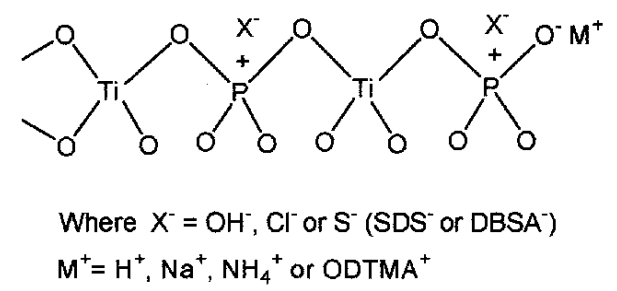

Figure 4. Proposed framework structure of titanium phosphates. 
size (i.e. a relatively high external surface area to volume ratio and reduced mass transfer resistance) are prerequisite for such efficient liquid phase oxidation catalysts. Me-TCM-7 was used (chosen because of its relatively high surface area and hydrophobicity) for the liquid phase oxidation of cyclohexene using a dilute $\mathrm{H}_{2} \mathrm{O}_{2}$ (25\% aqueous) oxidant under mild conditions $(333 \mathrm{~K})$. In a typical reaction 76 mole\% of cyclohexene was converted into 1,2-cyclohexanediol (dihydroxylation product, with $88 \%$ selectivity) and 2-cyclohexene-1-ol (allylic oxidation product, with $12 \%$ selectivity). The catalytically active site for such liquid phase oxidation reactions in the presence of dilute $\mathrm{H}_{2} \mathrm{O}_{2}$ is the tetrahedral $\mathrm{Ti}^{27}$, which generates the titanium hydroperoxo ${ }^{28}$ species in situ. This titanium hydroperoxo species in turn oxidizes the olefin to the corresponding epoxide. The formation of 1,2-cyclohexanediol, which was observed as a major product under the present reaction conditions, can be attributed to the acid/base-catalysed hydrolysis of the cyclohexene oxide generated at the initial stage. This high catalytic activity of Me-TCM-7 in liquid phase oxidation reaction in the presence of $\mathrm{H}_{2} \mathrm{O}_{2}$ as an oxidant also suggests that the tetrahedral nature of $\mathrm{Ti}$ in these titanium phosphate materials, as molecular sieves containing octahedral Ti (e.g. ETS-10) ${ }^{29}$ is completely inactive for such reactions.

3.3b Photo-catalysis: The energy gaps in the mesoporous titanium phosphates were estimated to be $\approx 3.8 \mathrm{eV}$ from the adsorption edge $(330 \mathrm{~nm})$ in the UV-Vis spectrum, which was larger than that of $\mathrm{TiO}_{2}(\approx 3.0 \mathrm{eV})$. The UV-light absorption property of these titanium phosphate molecular sieves together with the very large surface area and ionexchange property is very useful for their application as photocatalysts, such as in $\mathrm{H}_{2}$ evolution ${ }^{11,12}$ from water. The uniform pores along with the large internal surface area of these materials should make them accessible to water molecules, and the highly charged structure (1:1 correspondence of $\mathrm{Ti}$ and $\mathrm{P}$ ) existing on the surface of a catalyst should facilitate the charge separation process essential for the photodecomposition of water. Well-known photocatalyst $\mathrm{Pt}-\mathrm{TiO}_{2}$ or $\mathrm{Cu}-\mathrm{ZnS}$ catalysts in the presence of stronger $400 \mathrm{~W} \mathrm{Hg}$ lamp are used for the photocatalytic $\mathrm{H}_{2}$ evolution from water. Use of sacrificial agents like $\mathrm{SO}_{3}^{2-}$ and $\mathrm{S}^{2-30}$ enhances the rate of hydrogen evolution from

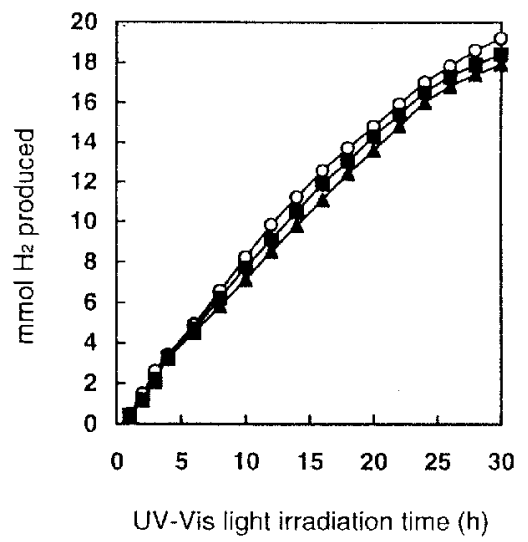

Figure 5. Time course for three successive photocatalytic run on TCM-7 (sample 1); reaction mixture composed of $175 \mathrm{ml}$ water and $5 \cdot 3 \mathrm{~g} \mathrm{Na}_{2} \mathrm{SO}_{3}$, light source $300 \mathrm{~W}$ Xe lamp. Points for first, second, third cycles are indicated by empty cycles, filled cycles and filled triangles, respectively. 
water. Here, photocatalytic $\mathrm{H}_{2}$ evolution from water under UV-Vis light irradiation over this mesoporous titanium phosphates using $\mathrm{Na}_{2} \mathrm{SO}_{3}$ as sacrificial agent is reported. In figure 5, the time course for three successive photocatalytic reactions using aqueous sodium sulphite is shown. $19 \cdot 2 \mathrm{mmol}$ of $\mathrm{H}_{2}$ was produced per gram of catalyst in $30 \mathrm{~h}$ irradiation by $300 \mathrm{~W}$ Xe lamp in the first cycle. The reaction mixture was composed of $175 \mathrm{ml}$ water, $5.3 \mathrm{~g} \mathrm{Na}_{2} \mathrm{SO}_{3}$ and $1 \mathrm{~g}$ catalyst at room temperature without $\mathrm{Pt}$ loading. The photocatalytic activity over TCM-7 remained almost same after three catalytic cycles (19.2, 18.6 and $18.1 \mathrm{mmol} \mathrm{g}^{-1}$ using $\mathrm{Na}_{2} \mathrm{SO}_{3}$ in the first, second and third run, respectively). The total amount of $\mathrm{H}_{2}$ evolutions for three successive cycles $(55.9 \mathrm{mmol})$ were larger than the total amount of Ti or P atom of the catalyst used in the present study $(5.3 \mathrm{mmol})$, indicating that the $\mathrm{H}_{2}$ evolved reaction took place catalytically in the titanium phosphate surface. The amount of $\mathrm{H}_{2}$ produced from pure water without any sacrificial agent was $182 \mu \mathrm{mol}$ in $24 \mathrm{~h} . \mathrm{O}_{2}$ was not detected. A blank run involving aqueous $\mathrm{Na}_{2} \mathrm{SO}_{3}$ solution in the absence of any catalyst under identical condition produces marely $6.7 \mathrm{mmol}$ of $\mathrm{H}_{2}$ for $30 \mathrm{~h}$ irradiation. These results suggest that (i) the novel mesoporous titanium phosphate is efficient photocatalyst for the $\mathrm{H}_{2}$ evolution from water in the presence of a sacrificial agent, (ii) in the presence of catalyst a three fold amount of $\mathrm{H}_{2}$ was produced than that in its absence, (iii) loading of a novel metal (e.g. Pt etc.) is not necessary vis-à-vis other $\mathrm{Ti}$ and $\mathrm{Zr}$-based photocatalysts. A possible explanation for such unique photocatalytic activity of this mesoporous titanium phosphate is that the uniform pore opening allows the large internal surface area of these materials to be accessible to the water molecules. Moreover, the highly charged structure due to $1: 1$ coordination of $\mathrm{Ti}$ and $\mathrm{P}$ associated with high defect $\mathrm{P}^{-} \mathrm{O}^{-} \mathrm{H}^{+}$density in the surface of the catalyst helps the charge separation process essential during photoreduction of water.

\section{Conclusion}

Mesoporous titanium phosphates can be synthesized using both cationic and anionic surfactants as SDAs. While $\mathrm{TiCl}_{4}$ is a suitable Ti source for anionic surfactants, Tialkoxide is the most suitable for the synthesis of these mesoporous titanium phosphates in the presence of cationic surfactants. UV absorption studies revealed that most of the Ti in these titanium phosphate materials is tetrahedrally coordinated. These mesoporous titanium phosphate materials have a very high surface area accessible through alternate regular coordination of $\mathrm{TiO}_{4}$ and $\mathrm{PO}_{4}$ tetrahedras. These novel materials have very high anion exchange capacities coupled with moderately good cationic defect sites. These materials show excellent catalytic activity in liquid phase oxidation reactions using dilute $\mathrm{H}_{2} \mathrm{O}_{2}$, they also show unique phocatalytic activity in the evolution of $\mathrm{H}_{2}$ by photoreduction of water.

\section{Acknowledgements}

$\mathrm{AB}$ would like to thank Prof P Banerjee for helpful discussions.

\section{References}

1. Barrer R M 1982 Hydrothermal chemistry of zeolites (New York: Academic Press)

2. Szostak R 1989 Molecular sieves: Principles of synthesis and identification (New York: Van Nostrand Reinhold) 
3. Corma A 1997 Chem. Rev. 972373

4. Wilson S T, Lok M M, Messina C A, Cannan T R and Flanigen E M 1982 J.Am.Chem. Soc. 1041146

5. Davis M E, Saldarriaga C, Montes C, Garces J and Crowder C 1988 Nature (London) 331698

6. Ekambaram S and Sevov S C 1999 Angew. Chem., Int. Ed. Engl. 38372

7. Matsushita T, Ebitani K and Kaneda K 1999 Chem. Commun. 265

8. Holland B T, Isbester P K, Blanford C F, Munson E J and Stein A 1997 J.Am.Chem. Soc. 119 6796

9. Kron D A, Holland B T, Wipson R, Maleke C and Stein A 1999 Langmuir 158300

10. Domen K, Kudo A and Onishi T 1986 J. Catal. 10292

11. Anpo M, Yamashita H, Ichihashi Y, Fujii Y and Honda M 1997 J. Phys. Chem. B101 2632

12. Zou Z, Ye J, Sayama K and Arakawa H 2001 Nature (London) 414625

13. Venuto P B 1994 Microporous Mater. 2297

14. Clearfield A and Costantino U 1996 Comprehensive supramolecular chemistry (Amsterdam: Elsevier) vol. 7, p. 107

15. Serre C and Ferey G 1999 J. Mater. Chem. 9579

16. Thieme M and Schüth T 1999 Microproous Mesoprous Mater. 29193

17. Bhaumik A and Inagaki S $2001 \mathrm{~J}$. Am. Chem. Soc. 123691

18. Inagaki S, Guan S, Fukushima Y, Ohsuna T and Terasaki O 1999 J. Am. Chem. Soc. 1219611

19. Asefa T, MacLachlan M J, Coombs N and Ozin G A 1999 Nature (London) 402867

20. Kresge C T, Leonowicz Roth W J, Vartuli J C and Beck J S 1992 Nature (London) 359710

21. Zhang W, Fröba M, Wang J, Tenev P T, Wong J and Pinnavaia T J 1996 J.Am. Chem. Soc. 1189164

22. Sayari A, Moudrakovski I and Reddy J S 1996 Chem. Mater. 82080

23. Kosuge K and Sing P S 1999 J. Phys. Chem. 1033563

24. Huo Q, Margolese D I and Stucky G D 1996 Chem. Mater. 81147

25. Inagaki S and Fukushima Y 1998 Microporous Mesoporous Mater. 21667

26. Ribeiro Carrott M M L, Estevao Candeias A J, Carrott P J M and Unger K K 1999Langmuir 158895

27. Notari B 1996 Advances in catalysis (San Diego, CA: Academic Press) vol. 41, p. 253

28. Bhaumik A, and Tatsumi T 1999 J. Catal. 182349

29. Anderson M W, Terasaki O, Oshuna T, Philippou A, MacKay S P, Ferreira A, Rocha J and Lidin S 1994 Nature (London) 367347

30. Kudo A and Sekizawa M 1999 Catal. Lett. 58241 